\title{
SISTEMA MULTICOMUTADO DE ANÁLISE EM FLUXO PARA DETERMINAÇÃO DE AMÔNIO E MONOCLORAMINA EM ÁGUAS RESIDUAIS E PRODUTOS DE DESINFECÇÃO
}

\author{
Sivanildo da Silva Borges \\ Centro de Ciências Exatas e Tecnológicas, Universidade Federal do Recôncavo da Bahia, 44380-000 Cruz das Almas - BA, \\ Brasil
}

Maria Soledad Moura Soares Fernandez Acevedo e Mauro Korn*

Departamento de Ciências Exatas e da Terra, Universidade do Estado da Bahia, R. Silveira Martins 2555, 41195-001 Salvador BA, Brasil

Recebido em 16/5/08; aceito em 8/12/08; publicado na web em 7/5/09

\begin{abstract}
MULTICOMMUTED FLOW SYSTEM FOR AMMONIUM AND MONOCHLORAMINE DETERMINATIONS IN WASTEWATER AND DISINFECTION PRODUCTS. A binary sampling flow analysis system equipped with gas diffusion cell was developed for $\mathrm{NH}_{4}^{+}$ and/or $\mathrm{NH}_{2} \mathrm{Cl}$ determination in wastewater and disinfection products samples based on the Berthelot reaction of the $\mathrm{NH}_{2} \mathrm{Cl}$ diffused through the semi-permeable PTFE membrane. The effect of the analytical conditions related to the reaction and flow parameters were evaluated and $\mathrm{N}_{-} \mathrm{NH}_{4}{ }^{+}$and $\mathrm{N}-\mathrm{NH}_{2} \mathrm{Cl}$ were determined in concentration ranges from 0.17 to $5 \mathrm{mg} \mathrm{L}^{-1}$ and from 0.5 to $14.5 \mathrm{mg}$ $\mathrm{L}^{-1}$, respectively. Limits of detection $(3 \sigma)$ of 50 and $140 \mu \mathrm{g} \mathrm{L}-1$ for $\mathrm{N}^{-\mathrm{NH}_{4}+}$ and $\mathrm{N}-\mathrm{NH}_{2} \mathrm{Cl}$ were calculated, respectively, and RSD of 5 and $2 \%$ were calculated for 10 consecutive determinations of $\mathrm{N}^{-\mathrm{NH}_{4}^{+}}\left(1\right.$ and $\left.3 \mathrm{mg} \mathrm{L}^{-1}\right)$ and $\mathrm{N}-\mathrm{NH}_{2} \mathrm{Cl}\left(3\right.$ and $\left.9 \mathrm{mg} \mathrm{L}^{-1}\right)$, respectively with 30 determinations $\mathrm{h}^{-1}$.
\end{abstract}

Keywords: monochloramine determination; ammonium determination; multicommutation.

\section{INTRODUÇÃO}

Cloraminas inorgânicas são produzidas pela reação entre $\mathrm{Cl}_{2} \mathrm{e}$ $\mathrm{N}$-amoniacal, ${ }^{1}$ sendo encontradas em produtos de desinfecção e em águas submetidas ao processo de cloração. ${ }^{2-4} \mathrm{~A}$ análise de águas em plantas de tratamento de efluentes é uma forma efetiva de controle da eficácia de procedimentos de desinfecção e a concentração de $\mathrm{N}$-amoniacal é um dos parâmetros que deve ser monitorado. $\mathrm{O} \mathrm{N}$ amoniacal é encontrado em esgotos urbanos, na faixa de concentração entre 5 e $50 \mathrm{mg} \mathrm{L}^{-1} .5$

Entre as cloraminas, a monocloramina é a espécie preponderante em águas com pH superior a 5,5, sendo, em geral, detectada por técnicas eletroanalíticas, ${ }^{6,7}$ acoplada à HPLC,${ }^{8}$ ou, ainda, a sistemas FIA. ${ }^{9}$ Alguns procedimentos espectrofotométricos para a determinação de monocloramina são reportados na literatura, ${ }^{10-12}$ mas, corriqueiramente, as determinações em amostras de águas tratadas e residuais são executadas pela reação com $\mathrm{N}, \mathrm{N}^{\prime}$-dietil-p-fenilenediamina (método do DPD). ${ }^{12}$

Muitos procedimentos para determinação espectrofotométrica de $\mathrm{NH}_{4}^{+}$são baseados na reação de Berthelot. ${ }^{1,13,14} \mathrm{O}$ método de Berthelot envolve a monitoração do azul de indofenol produzido, em meio alcalino, pela reação entre $\mathrm{N}_{-} \mathrm{NH}_{4}^{+}$, fenol e hipoclorito, na presença de íons nitroprussiato. Este método vem sendo aplicado para a determinação de $\mathrm{NH}_{2} \mathrm{Cl}$ em amostras de águas. ${ }^{4,15}$

A separação do analito na forma de espécies voláteis é uma estratégia que leva ao aumento da seletividade. Sistemas em fluxo que fazem uso de técnicas de separação, como a difusão gasosa através de membranas semipermeáveis para a separação de $\mathrm{N}_{-} \mathrm{NH}_{4}^{+}$, foram aplicadas nas determinações $\mathrm{N}$-protéico em digeridos de plantas e em amostras de cerveja. ${ }^{\text {16-18 }}$

A amostragem binária é uma estratégia usada para maximizar a reação entre analito e reagente em sistemas de análise em fluxo, pela inserção consecutiva e alternada de sub-alíquotas da amostra e reagente. ${ }^{19}$ Trabalhos publicados anteriormente evidenciaram uma série de vantagens do emprego da amostragem binária nos sistemas multicomutados de análises em fluxo e entre essas se destacam o aumento da produtividade e da sensibilidade analítica, além da diminuição do volume de reagente e da quantidade de resíduo gerado. ${ }^{20,21}$ Neste trabalho foram avaliados procedimentos para determinações dos teores de monocloramina e amônio em produtos de desinfecção e em águas residuais sem tratamento prévio das amostras, explorando a difusão da monocloramina em sistema multicomutado de análises em fluxo.

\section{PARTE EXPERIMENTAL}

\section{Equipamentos}

O diagrama do sistema de fluxo empregado para as determinações de $\mathrm{N}-\mathrm{NH}_{2} \mathrm{Cl}$ e $\mathrm{N}-\mathrm{NH}_{4}{ }^{+}$é apresentado na Figura 1a. O módulo de análises foi constituído por um conjunto de cinco válvulas solenóide de três vias modelo 161T031 (NResearch, EUA); bomba peristáltica Minipuls 3 com 4 canais (Gilson, França); câmara de difusão gasosa (Figura 1b); linhas de transmissão em polietileno $(0,8 \mathrm{~mm}$ de diâmetro interno) e, espectrofotômetro Femto 700 plus (Femto, Brasil), equipado com célula de fluxo com capacidade para $180 \mu \mathrm{L}$ e caminho óptico de $10 \mathrm{~mm}$. A câmara de difusão gasosa (Figura 1b) foi construída no próprio laboratório, seguindo modelos anteriormente reportados na literatura. ${ }^{16-18}$

Um microcomputador Pentium I equipado com interface PCL 711-S (Advantech, Taiwan) foi empregado para controle e sincronização do acionamento das válvulas solenóide com a posição dos roletes da bomba peristáltica, bem como para a aquisição dos sinais gerados pelo espectrofotômetro. Uma interface de potência foi construída para o acionamento das válvulas solenóide. Um programa em linguagem QuickBASIC 4.5 foi desenvolvido para a comutação das vias das válvulas solenóide e aquisição de sinais. 


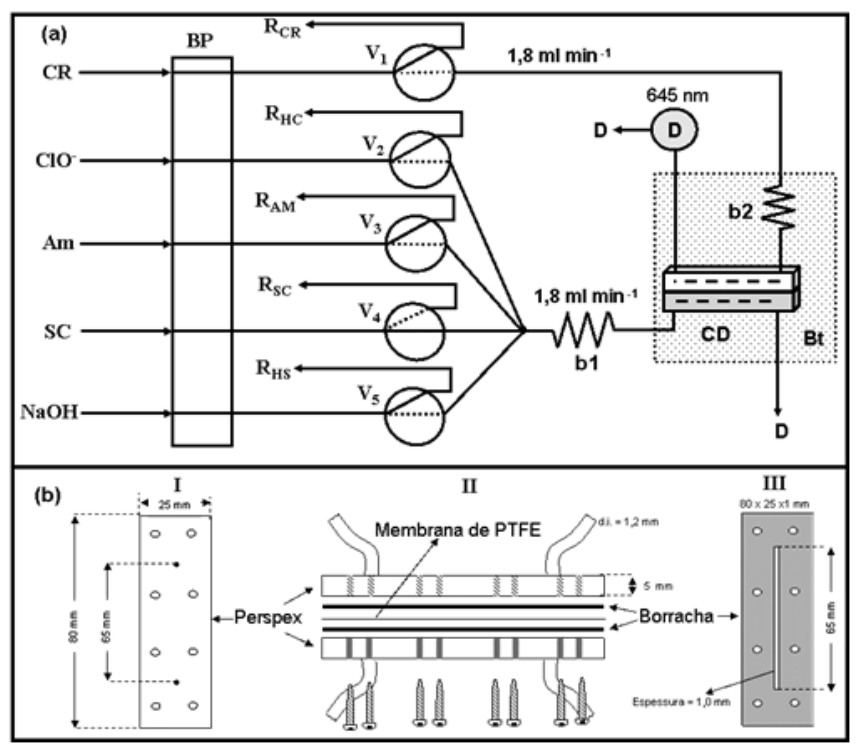

Figura 1. Diagrama de fluxo (a) e detalhes da câmara de difusão gasosa (b). $\operatorname{Em}(a): A m=$ Amostra. $R_{A M}=$ Reciclo da amostra. $C R=$ Coquetel de reagentes. $R_{C R}=$ Reciclo do coquetel de reagentes. $S C=$ Solução carregadora. $R_{S C}=$ Reciclo da solução carregadora. $R_{\mathrm{NaOH}}=$ Reciclo da solução de $\mathrm{NaOH}$. $R_{C l O}=$ Reciclo da solução de hipoclorito de sódio. $B P=$ Bomba peristáltica. $D=$ detector. $B t=$ Banho termostatizado. $C P=$ Câmara de permeação. $b 1 e$ b2 = Bobinas de $100 \mathrm{~cm} . V_{1}, V_{2}, V_{3}, V_{4}$ e $V_{5}=$ Válvulas solenóide de três vias. $W=$ Descarte. Em (b): $I$ = bloco de Perspex (vista frontal); $I I=$ câmara de permeação com todos os componentes (vista lateral); III = tira de borracha com $1 \mathrm{~mm}$ de espessura

\section{Reagentes e soluções}

Foram utilizados reagentes com grau analítico de pureza e todas as soluções foram sempre preparadas com água recém desionizada com condutividade $<0,1 \mu \mathrm{S} \mathrm{cm}^{-1}$. Solução estoque 100 $\mathrm{mg} \mathrm{L}^{-1}$ em $\mathrm{NH}_{4}^{+}$foi preparada pela dissolução de $\mathrm{NH}_{4} \mathrm{Cl}$ (Merck) em água. Soluções de trabalho com concentrações entre 0,1 a $20 \mathrm{mg} \mathrm{L}^{-1} \mathrm{em} \mathrm{NH}_{4}^{+}$foram preparadas pela diluição adequada da solução estoque.

Solução mista de salicilato $1,25 \mathrm{~mol} \mathrm{~L}^{-1}$ e $4 \times 10^{-4} \mathrm{~mol} \mathrm{~L}^{-1} \mathrm{em}$ nitroprussiato (Vetec) era preparada diariamente em $0,9 \mathrm{~mol} \mathrm{~L}^{-1} \mathrm{em}$ $\mathrm{NaOH}$ (Baker), a partir da dissolução da massa adequada de salicilato de sódio (Merck) e nitroprussiato de sódio (Vetec). Solução de hipoclorito $0,2 \%(\mathrm{~m} / \mathrm{m})$ foi obtida pela diluição de solução $10 \%$ em solução de $\mathrm{NaOH} 0,01 \mathrm{~mol} \mathrm{~L}^{-1}$. As soluções de hipoclorito empregadas eram livres de contaminações por cloraminas.

Amostras de produtos de desinfecção de uso doméstico e odontológico foram empregadas para avaliar a eficiência do procedimento de análise proposto. As determinações de $\mathrm{NH}_{2} \mathrm{Cl}$ foram realizadas após alcalinização das amostras de desinfetantes, pela adição, em linha, de solução de $\mathrm{NaOH}$, de forma que a concentração de $\mathrm{NaOH}$ nas amostras atingisse o valor de $0,01 \mathrm{~mol} \mathrm{~L}^{-1}$.

Para as determinações de amônio, as amostras de águas residuais foram misturadas, em linha, com solução de hipoclorito em meio alcalino. Para a avaliação do procedimento proposto, visando as determinações de monocloramina e amônio em amostras de desinfetantes e águas residuais, respectivamente, foi empregado o método da N,N'-dietil-p-fenilenediamina (DPD). Para tanto, foi preparada solução $0,1 \mathrm{~g} \mathrm{~L}^{-1}$ de DPD (Fluka), contendo KI (Quimex) $100 \mathrm{mg} \mathrm{L}^{-1}$ em meio de tampão fosfato ( $\mathrm{pH} \mathrm{6,3).}$

\section{Procedimentos}

O diagrama do sistema de fluxo empregado é apresentado na Figura 1a. As inserções das alíquotas das soluções da amostra e reagente foram realizadas pela sincronização do acionamento das válvulas solenóide com a posição dos roletes da bomba peristáltica.

O sistema de análises em fluxo foi concebido para permitir o reciclo das soluções de amostra e dos reagentes (Figura 1a) a 1,8 $\mathrm{mL} \mathrm{min}^{-1}$. As válvulas $\mathrm{V}_{1}, \mathrm{~V}_{2}, \mathrm{~V}_{3}, \mathrm{~V}_{4} \mathrm{e} \mathrm{V}_{5}$ foram acionadas para preenchimento das vias com as seguintes soluções: $\left(\mathrm{V}_{1}\right)$ solução do coquetel de reagentes; $\left(\mathrm{V}_{2}\right)$ solução de $\mathrm{ClO} ;\left(\mathrm{V}_{3}\right)$ amostra ou solução de referência de $\mathrm{NH}_{4}^{+} ;\left(\mathrm{V}_{4}\right)$ solução carregadora (água) e, $\left(\mathrm{V}_{5}\right)$ solução de $\mathrm{NaOH} 0,01$ mol L ${ }^{-1}$. Para a limpeza das vias a válvula $\mathrm{V}_{4}$ permaneceu acionada $\mathrm{e}$ as válvulas $\mathrm{V}_{2}, \mathrm{~V}_{3}$ e $\mathrm{V}_{5}$ foram desativadas, para interromper a inserção da solução de hipoclorito, amostra (ou solução de referência de amônio) e solução de $\mathrm{NaOH}$, respectivamente, no percurso analítico. Após esta etapa, $\mathrm{V}_{1}$ era acionada para limpeza da via de recepção com a própria solução receptora de $\mathrm{NH}_{2} \mathrm{Cl}$ (coquetel de reagentes), para evitar possíveis contaminações da solução receptora pela difusão de resíduos de $\mathrm{NH}_{2} \mathrm{Cl}$ através da membrana de PTFE. Ao desativar a válvula $\mathrm{V}_{1}$, uma alíquota do coquetel de reagentes era confinada no canal receptor da câmara de difusão gasosa (CP).

No procedimento proposto uma mesma curva de trabalho foi construída para as determinações de amônio e monocloramina. A construção da curva de trabalho foi conduzida mantendo $V_{4}$ desativada e acionando alternadamente por 15 ciclos as válvulas $\mathrm{V}_{2}$ e $\mathrm{V}_{3} \mathrm{em}$ intervalos de tempo de $1 \mathrm{~s}$, de modo a permitir a inserção consecutiva e alternada de 15 alíquotas da solução de hipoclorito e 15 alíquotas das soluções de referência de $\mathrm{NH}_{4}{ }^{+}$. $\mathrm{O}$ volume calculado de cada alíquota foi igual a 30 $\mu \mathrm{L}$. Após esta etapa as válvulas $\mathrm{V}_{2} \mathrm{eV}_{3}$ foram desativadas e a válvula $\mathrm{V}_{4}$ foi acionada para endereçar as alíquotas de hipoclorito e amônio para a bobina de reação (b1), com $100 \mathrm{~cm}$ de comprimento. Em seqüência, a mistura foi endereçada para CP, a qual era mantida imersa em banho termostatizado $(\mathrm{Bt})$ a $50{ }^{\circ} \mathrm{C}$. Deve-se ressaltar que quando a mistura alcançava $\mathrm{CP}$, as válvulas $\mathrm{V}_{1}, \mathrm{~V}_{2}, \mathrm{~V}_{3} \mathrm{eV}_{5}$ estavam desativadas e a $\mathrm{NH}_{2} \mathrm{Cl}$ produzida difundia através da membrana de PTFE para, então, reagir com a alíquota de coquetel de reagentes confinada no canal de recepção da $\mathrm{CP}$ para produção do indofenol. Para melhorar o rendimento da reação de produção do indofenol, o coquetel de reagentes era previamente aquecido na bobina b2 $(100 \mathrm{~cm})$ e após passagem da mistura por $\mathrm{CP}$, a válvula $\mathrm{V}_{4}$ era também desativada e o fluxo interrompido por $15 \mathrm{~s}$. Em seguida, $\mathrm{V}_{1}$ era acionada, endereçando o indofenol formado para a medida do sinal transiente $(645 \mathrm{~nm})$ e condicionando o canal receptor da CP para uma nova medida. Para a determinação de monocloramina (ou amônio) em outra solução, apenas $\mathrm{V}_{3}$ era acionada para permitir o preenchimento da linha com a nova solução. Com a desativação $\mathrm{de}_{3}$, após preenchimento da linha, $\mathrm{V}_{4}$ era acionada para limpeza do percurso após a confluência e uma nova determinação era iniciada.

Nas determinações de amônio, a amostra era admitida pela válvula $\mathrm{V}_{3}$ e a rotina empregada era a mesma aplicada para a construção da curva analítica. Para as determinações de monocloramina em amostras de desinfetantes a válvula $V_{2}$ permanecia desativada, enquanto que as válvulas $\mathrm{V}_{5}$ (solução de $\mathrm{NaOH} 0,01 \mathrm{~mol} \mathrm{~L}^{-1}$ ) e $\mathrm{V}_{3}$ (amostra) eram acionadas alternadamente pelo mesmo intervalo de tempo $(1 \mathrm{~s})$ e pelo mesmo número de ciclos (15).

Para validação do procedimento proposto foi empregado o método do DPD para a determinação de monocloramina, sendo o coquetel de reagentes no módulo de análise substituído por solução de DPD 0,1 g $\mathrm{L}^{-1}$ contendo KI. A mesma rotina empregada para o método proposto foi empregada nestas determinações, com exceção do aquecimento da solução no banho. O método do DPD é baseado na reação de $\mathrm{I}^{-}$com $\mathrm{NH}_{2} \mathrm{Cl}$ para gerar $\mathrm{I}_{2}$, o qual oxida o DPD, produzindo composto de coloração rósea $(515 \mathrm{~nm}){ }^{12,22,23}$ 


\section{RESULTADOS E DISCUSSÃO}

As condições adequadas para a determinação de $\mathrm{NH}_{2} \mathrm{Cl}$ e de $\mathrm{NH}_{4}^{+}$, como $\mathrm{NH}_{2} \mathrm{Cl}$, foram avaliadas. Para tanto, foram investigadas as vazões da solução carregadora e da solução do coquetel de reagentes, o tempo de interrupção do fluxo para a reação entre a monocloramina difundida e o coquetel de reagentes, a temperatura do banho termostatizado e o volume de amostra injetado no percurso analítico.

\section{Efeito da vazão}

Estudos de vazão foram realizados empregando-se duas bombas peristálticas. A primeira bomba foi utilizada para a propulsão da solução do coquetel de reagentes pelo compartimento superior da câmara de permeação e, a segunda, para a propulsão das soluções de amônio, hipoclorito e do carregador pelo compartimento inferior da câmara de permeação. Para estes ensaios as vazões de ambas as soluções dos compartimentos da câmara de permeação foram variadas na faixa entre 1,5 e 5,25 mL min ${ }^{-1}$ e os efeitos das variações das vazões sobre o sinal analítico podem ser observados na Figura 2. Dada a difusão do $\mathrm{NH}_{2} \mathrm{Cl}$ através da membrana de PTFE para reagir com a solução receptora (coquetel de reagentes), o aumento da vazão do carregador (água) acarretou em perda (80\%) do sinal analítico. Desta forma, foi selecionada a vazão de $1,8 \mathrm{~mL} \mathrm{~min}^{-1}$ para as soluções do coquetel de reagentes e da solução carregadora.

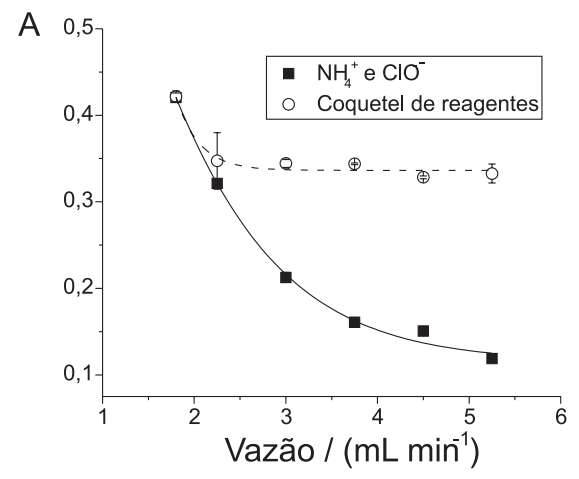

Figura 2. Efeito da vazão sobre o sinal analítico. $\mathrm{NH}_{4}^{+}=3 \mathrm{mg} \mathrm{L}^{-1}$; tempo de pulso $=1 \mathrm{~s}$; número de pulsos $=20$; temperatura de $40^{\circ} \mathrm{C}$

\section{Efeito da temperatura e do tempo de interrupção do fluxo na extensão da reação}

O efeito da temperatura sobre a extensão da reação foi avaliado paralelamente com o tempo de interrupção do fluxo da solução receptora por intervalos de tempo entre 15 e 60 s e variando-se a temperatura do banho termostatizado no qual a câmara de difusão gasosa estava imersa na faixa entre 30 e $50^{\circ} \mathrm{C}$. Assim, pôde ser observado aumento da quantidade de indofenol produzido com o aumento da temperatura (Figura 3), concordando com informações anteriormente reportadas. ${ }^{24}$ Para não comprometer a produtividade e a sensibilidade analítica foram selecionadas a temperatura do banho em $50^{\circ} \mathrm{Ce} 15 \mathrm{~s}$ de interrupção do fluxo da solução do coquetel de reagentes.

\section{Parâmetros da multicomutação}

Uma vez que o volume de amostra e da solução de hipoclorito, bem como do tamanho das alíquotas durante a multicomutação influenciariam na concentração da monocloramina produzida e permeada através da membrana de PTFE, foram realizados estudos para otimização destas

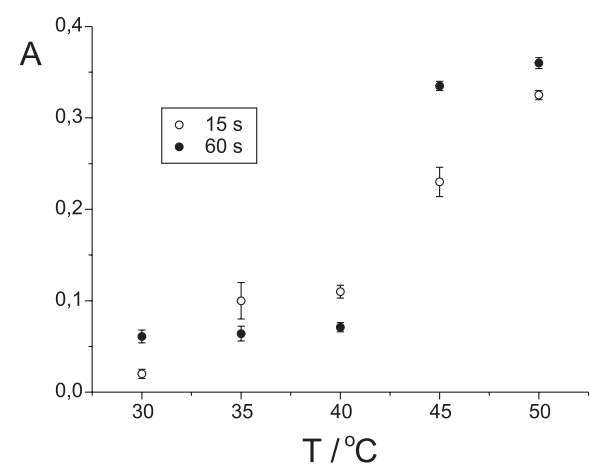

Figura 3. Variação do sinal analítico com a temperatura de reação para intervalos de tempo de reação de 15 e $60 \mathrm{~s} . \mathrm{NH}_{4}^{+}=3 \mathrm{mg} \mathrm{L}^{-1}$; tempo de pulso $=1$; número de pulsos $=20$; vazão em todos os canais de 1,8 $\mathrm{mL} \mathrm{min}^{-1}$

variáveis, mantendo-se o comprimento da bobina b1 inalterado. Desta forma, foi avaliada a influência do tamanho dos pulsos de amostra e de solução de hipoclorito sobre o sinal analítico para inserção de volume de amostra correspondente a $10 \mathrm{~s}$ de amostragem de cada solução, para pulsos de acionamentos das respectivas válvulas variando de 0,1 a $1 \mathrm{~s}$ (Figura 4). O tamanho das sub-alíquotas (pulsos) da amostra e da solução de hipoclorito influenciaram significativamente sobre a magnitude dos sinais analíticos e precisão das medidas. Assim, apesar de sinais analíticos mais intensos serem obtidos para pulsos de $0,2 \mathrm{~s}$ de duração, foram selecionados intervalos de tempo de acionamento das válvulas de 0,5 e 1,0 s para estudos posteriores, visto a melhoria da precisão para ambas as condições (Figura 4).

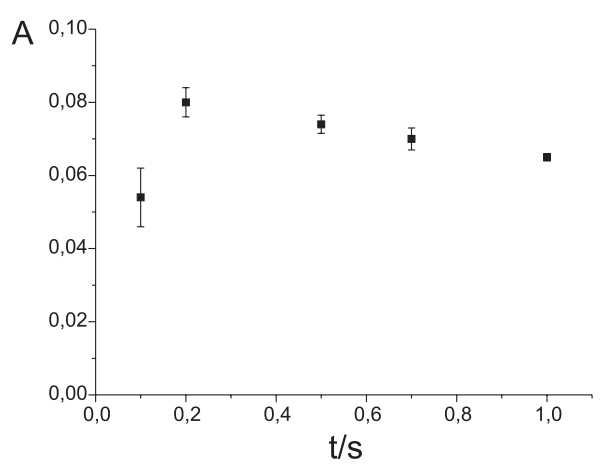

Figura 4. Influência do tempo de pulso para a amostragem binária da solução de $\mathrm{NH}_{4}^{+}$e da solução de $\mathrm{ClO}^{-}$sobre do sinal analítico para tempo de amostragem de $10 \mathrm{~s}$. $\mathrm{NH}_{4}^{+}=3 \mathrm{mg} \mathrm{L}^{-1}$; vazão em todos os canais de $1,8 \mathrm{~mL}$ min $^{-1} ;$ temperatura $=50^{\circ} \mathrm{C}$

A influência do volume de amostra inserida no percurso analítico sobre o sinal analítico foi investigada. Intervalos de tempo de amostragem de 5 a $20 \mathrm{~s}$ para pulsos de 0,5 e $1,0 \mathrm{~s}$ foram avaliados e os resultados podem ser observados na Figura 5. O aumento do intervalo de tempo de amostragem levou ao aumento significativo dos sinais analíticos para tempo total de amostragem de até $15 \mathrm{~s}$. Entretanto, os desvios padrão para medidas dos sinais analíticos empregandose tempo de pulso de 0,5 foram maiores quando comparados com os desvios das medidas realizadas com tempo de pulso de 1,0 s. Desta forma, para o desenvolvimento dos procedimentos para a determinação de $\mathrm{NH}_{2} \mathrm{Cl}$ ou $\mathrm{NH}_{4}{ }^{+}$foi selecionado tempo de pulso de acionamento das válvulas de $1,0 \mathrm{~s}$ e tempo total de multicomutação das válvulas de $30 \mathrm{~s}$, correspondendo à inserção de $450 \mu \mathrm{L}$ da amostra (15 s a $\left.1,8 \mathrm{~mL} \mathrm{~min}^{-1}\right)$. 


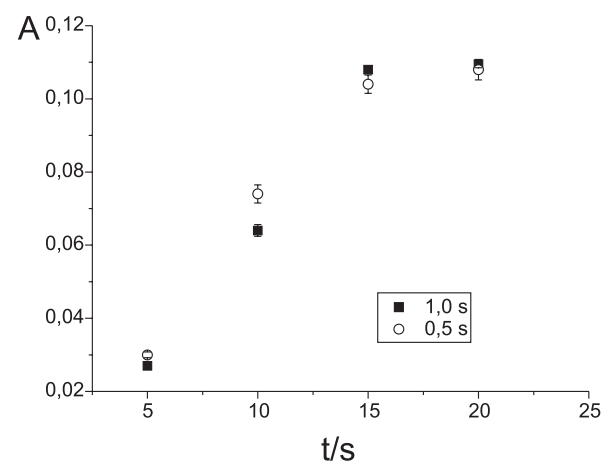

Figura 5. Influência do tempo de amostragem da solução de $\mathrm{NH}_{4}^{+}$e da solução de $\mathrm{ClO}^{-}$sobre do sinal analítico. $\mathrm{NH}_{4}^{+}=3 \mathrm{mg} \mathrm{L}^{-1}$; tempo de pulso $=1 \mathrm{~s}$;

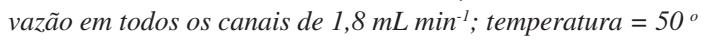

\section{Figuras de mérito}

As figuras de mérito para a determinação de $\mathrm{NH}_{2} \mathrm{Cl}$ e/ou $\mathrm{NH}_{4}^{+}$ foram estabelecidas para tempo de reação de $15 \mathrm{~s}$, temperatura do banho de $50{ }^{\circ} \mathrm{C}$, vazão em todos os canais de $1,8 \mathrm{~mL} \mathrm{~min}^{-1}$, tempo de pulso de acionamento das válvulas de $1 \mathrm{~s}$ e $450 \mu \mathrm{L}$ de amostra inserida no percurso analítico. Desta forma, empregando-se o sistema de análises em fluxo representado na Figura 1a, a faixa dinâmica de trabalho foi de 0,2 a 5,0 $\mathrm{mg} \mathrm{L}^{-1} \mathrm{em} \mathrm{NH}_{4}^{+}(\mathrm{A}=0,0047$ $\left.+0,0271 . \mathrm{C}_{\mathrm{NH} 4+}, \mathrm{R}=0,9998\right)$ e de 0,5 a $14,5 \mathrm{mg} \mathrm{L}^{-1}(\mathrm{~A}=0,0047$ $\left.+0,0095 . \mathrm{C}_{\mathrm{NH} 2 \mathrm{Cl}}, \mathrm{R}=0,9998\right)$. A faixa dinâmica de trabalho para monocloramina, bem como a equação da reta foram encontradas pela aplicação do fator 2,86 sobre as concentrações de amônio. Este fator foi calculado pela relação entre as massas molares de $\mathrm{NH}_{2} \mathrm{Cl}$ e $\mathrm{NH}_{4}^{+}(51,45 / 18)$.

Os procedimentos propostos apresentaram limites de detecção $(3 \sigma)$ de 50 e $140 \mu \mathrm{g} \mathrm{L}^{-1}$ para $\mathrm{NH}_{4}^{+}$e $\mathrm{NH}_{2} \mathrm{Cl}$, respectivamente. Para 10 determinações consecutivas de $\mathrm{NH}_{4}^{+}\left(1\right.$ e $\left.3 \mathrm{mg} \mathrm{L}^{-1}\right)$ e de $\mathrm{NH}_{2} \mathrm{Cl}$ (2,9 e $\left.8,6 \mathrm{mg} \mathrm{L}^{-1}\right)$ os desvios padrão relativos foram de 5 e $2 \%$, respectivamente. Para ambos os procedimentos a produtividade analítica foi de 30 determinações $\mathrm{h}^{-1}$ de $\mathrm{N}_{-} \mathrm{NH}_{4}^{+}$eu $\mathrm{NH}_{2} \mathrm{Cl}$ nas faixas de concentração de 0,17 a $5 \mathrm{mg} \mathrm{L}^{-1}$ e de 0,5 a $14,5 \mathrm{mg} \mathrm{L}^{-1}$, respectivamente.

\section{Aplicações}

Nas amostras de desinfetantes (hipoclorito) foram determinadas as concentrações de monocloramina, uma vez que seria praticamente impossível a presença de íons amônio em tais amostras com altas concentrações de $\mathrm{ClO}^{-}$. Na Tabela 1 são apresentadas as concentrações de monocloramina. Os dados encontrados apontam para a presença deste analito em concentrações em torno de $1 \mathrm{mg} \mathrm{L}^{-1}$ para o tipo de amostra analisada.

Tabela 1. Concentração de $\mathrm{NH}_{2} \mathrm{Cl}$ em amostras de desinfetantes de uso doméstico

\begin{tabular}{lc} 
Amostra & Concentração $\left(\mathrm{mg} \mathrm{L}^{-1}\right)$ \\
\hline A & $1,03 \pm 0,04$ \\
B & $0,94 \pm 0,04$ \\
C & $0,72 \pm 0,02$ \\
D & $1,06 \pm 0,04$ \\
\hline
\end{tabular}

( $\mathrm{N}=3$ e $95 \%$ de confiabilidade)
Para validação do procedimento proposto foi adotado procedimento de referência baseado na reação com DPD. ${ }^{12}$ As figuras de mérito para o procedimento de referência e o procedimento proposto são apresentadas na Tabela 2, onde pode ser observado que o procedimento proposto apresentou desempenho superior ao do método de referência.

Tabela 2. Figuras de mérito do método proposto e de referência (método do DPD)

\begin{tabular}{lcccc}
\hline $\begin{array}{l}\text { Figuras de } \\
\text { mérito }\end{array}$ & \multicolumn{2}{c}{ Método proposto } & \multicolumn{2}{c}{ Método DPD } \\
& $\mathrm{NH}_{4}^{+}$ & $\mathrm{NH}_{2} \mathrm{Cl}$ & $\mathrm{NH}_{4}^{+}$ & $\mathrm{NH}_{2} \mathrm{Cl}$ \\
\hline $\begin{array}{l}\text { Sensibilidade, } \\
\text { uA L mg }\end{array}$ & 0,0272 & 0,0095 & 0,0159 & 0,0056 \\
$\mathrm{R}$ & 0,9998 & 0,9998 & 0,9993 & 0,9993 \\
$\begin{array}{l}\text { Faixa linear, } \\
\text { mg L }\end{array}$ & $0,17-5$ & $0,5-14,5$ & $0,3-5$ & $1,0-14,5$ \\
RSD, \% & $<4$ & $<4$ & $<2$ & $<2$ \\
LOD, $\mu \mathrm{g} \mathrm{L} \mathrm{L}^{-1}$ & 50 & 140 & 100 & 290 \\
\hline
\end{tabular}

Três amostras de águas residuais coletadas junto à empresa de saneamento de Salvador-BA foram previamente filtradas e diluídas 10 vezes, para as posteriores determinações de amônio e monocloramina. No entanto, a monocloramina não foi detectada em nenhuma das amostras analisadas. A impossibilidade de detecção de monocloramina pode ser explicada pela elevada concentração de matéria orgânica oxidável nas amostras analisadas e pela alta capacidade oxidante da monocloramina. Na Tabela 3 são apresentadas as concentrações de amônio obtidas pelos métodos proposto e de referência. Os valores obtidos foram concordantes para $95 \%$ de confiança.

Tabela 3. Concentração de amônio em diferentes amostras de águas residuais empregando o método proposto e o de referência (DPD)

\begin{tabular}{lcc}
\hline $\begin{array}{l}\text { Amostra de água } \\
\text { residual }\end{array}$ & $\begin{array}{c}\text { Método Proposto } \\
\left(\mathrm{mg} \mathrm{L}^{-1}\right)\end{array}$ & $\begin{array}{c}\text { Método do DPD } \\
\left(\mathrm{mg} \mathrm{L}^{-1}\right)\end{array}$ \\
\hline A & $19,6 \pm 0,7$ & $15,5 \pm 0,5$ \\
B & $15,5 \pm 0,6$ & $16,9 \pm 0,7$ \\
C & $37 \pm 2$ & $36 \pm 1$ \\
\hline
\end{tabular}

( $\mathrm{n}=3$ e $95 \%$ de confiabilidade)

\section{CONCLUSÕES}

O procedimento de análise em fluxo proposto é inédito na exploração da permeação da monocloramina para a determinação desta espécie e de amônio em amostras diversas. O procedimento mostrou-se útil para a análise de amostras de diferentes origens, sem a necessidade de laboriosa etapa de pré-tratamento da amostras. Assim, uma simples filtração (e/ou diluição) foi suficiente para evitar entupimento das vias da válvula solenóide. A monitoração de monocloramina e amônio com o procedimento proposto pôde ser realizada em amostras com elevada turbidez e elevado teor salino.

A permeação da monocloramina em sistema de análise em fluxo permitiu a determinação espectrofotométrica de monocloramina em produtos para desinfecção de uso doméstico contendo hipoclorito em elevadas concentrações e de amônio em águas residuais com elevado teor de matéria orgânica oxidável. 


\section{AGRADECIMENTOS}

PRONEX, CNPq, FAPESB.

\section{REFERENCIAS}

1. Patton, C. J.; Crouch, S. R.; Anal. Chem. 1977, 49, 464.

2. Chen, X.; Stewart, P. S.; Water Res. 2000, 34, 4229.

3. Chandy, J. P.; Angles, M. L.; Water Res. 2001, 35, 2677.

4. Harp, D. L.; Water Environ. Res. 2000, 6, 706.

5. Cerdá, A.; Oms, M. T.; Forteza, R.; Cerdá, V.; Anal. Chim. Acta 1995, $311,165$.

6. Ge, H.; Wallace, G. G.; O’Halloran, R. A. J.; Anal. Chim. Acta 1990, 237,149

7. Piela, B.; Wrona, P. K.; J. Electrochem. Soc. 2003, 150, 255.

8. Brunetto, M.; Colin, C.; Rosset, R.; Analusis 1987, 15, 165.

9. Buck, S.; Stein, K.; Schwedt, G.; Anal. Chim. Acta 1999, 390, 141.

10. Czech, F. W.; Fuchs, R. J.; Antczak, H. F.; Anal. Chem. 1961, 33, 705.

11. Ferriol, M.; Gazet, J.; Anal. Chim. Acta 1988, 209, 321.

12. American Public Health Association - APHA, AWWA, WEF; Standard methods for the examination of water and wastewater, $18^{\text {th }}$ ed., APHA: Washington, 1992.

13. Harfmann, R. G.; Crouch, S. R.; Talanta 1989, 36, 261.

14. Searcy, R. L.; Reardon, J. E.; Foreman, J. A.; J. Am. Med. Technol. 1967, $33,15$.

15. Tao, H.; Chen, Z. L.; Li, X.; Yang, Y. L.; Li, G. B.; Anal. Chim. Acta 2008, 615, 184

16. Nakata, R.; Kawamura, T.; Sakashita, H.; Nitta, A.; Anal. Chim. Acta 1988, 208, 81

17. Pasquini, C.; De Faria, L. C.; Anal. Chim. Acta 1987, 193, 19.

18. Wang, L.; Cardwell, T. J.; Cattrall, R. W.; Luque de Castro, M. D.; Kolev, S. D.; Talanta 2003, 60, 1269.

19. Reis, B. F.; Giné, M. F.; Zagatto, E. A. G.; Lima, J. L. F. C.; Lapa, R. A.; Anal. Chim. Acta 2001, 293, 129.

20. Rocha, F. R. P.; Martelli, P. B.; Reis, B. F.; Anal. Chim. Acta 2001, 438, 11.

21. Borges, S. S.; Reis, B. F.; Anal. Chim. Acta 2007, 600, 66.

22. Carlsson, K.; Moberg, L.; Karlberg, B.; Water Res. 1999, 33, 375.

23. Moberg, L.; Karlberg, B.; Anal. Chim. Acta 2000, 407, 127.

24. Luca, G. C.; Reis, B. F.; Quim. Nova 2001, 24, 191. 